\title{
Mis on laim ja mida tähendab laimama
}

\author{
LEMBIT VABA
}

EKSS ütleb, et laim : laimu on 'laimamine; laimavad sõnad, laimav jutt'. Seda selgitust toetavad näitelaused See on alatu, solvav, räpane, tige laim. Ära aja laimu! Laimu levitama, külvama. Laim on karistatav. Samal ajal on laim eesti õigustermin, mille tähendussisu on 'teadvalt vale ja teist isikut häbistava väljamõeldise levitamine' (Esterm). laimama : laimata sisu avab EKSS aga nii: 'kellegi kohta valet, häbistavat väljamõeldist levitama'.

Sünonüümisõnastikus on laim esindatud sünonüümireaga laimdus van, laimujutt, patujutt, valesüüdistus, teotus, insinuatsioon, insinueering, fabritseering, paharääkimine; verbi laimama sünonüümirea liikmed on mustama, tõrvama, teotama, rüvetama, määrima, \{kellegi kohta\} laimujuttu rääkima, \{kellelegi\} seitset surmapattu sü̈̈ks panema, soppa kaela loopima, sopaga üle valama (kallama), poriga üle valama (kallama), poriga pilduma (loopima), mudaga pilduma (loopima), \{kellestki\} halvasti rääkima, insinueerima, solki kaela valama (kallama), täis pasandama (SYS).

laim kuulub tänapäeva eesti keeles 10000 sagedama sõna hulka, laimama sellesse seltskonda ei mahu (Kaalep, Muischnek 2002). Ent eesti vanem leksikograafia noteerib üksnes verbi: Laimama Verleumden (Vestring 1998 [1710-1730]: 107), laimama verläumden, verspotten (Thor Helle 1732: 127). 1739. aasta piiblitõlkes on verb laimama ja teonimi laimamine sage, kuid sealgi puudub laim (Piiblisõnastik). Seevastu regilaulukeelele on omased nii laim kui ka laimama: Isalaste soimamisi, / Emalaste laimamisi: / Isalaste soim on suuri, / Emalaste laim on laia, / Tütärde tiutis korki ['kõrk'] (Kuusalu, ERA); lapsed laimuta lihavad, / Neiud noomita nobedad (Viru-Jaagupi, ERL III/1: 22); Kurjas minda kutsutakse, / Õelaks minda üteltakse / Laisaks minda laimatakse (Paistu, ERL III/1: 206).

laim ja laimama on EMS-i järgi ülemaaliselt tuntud. Hakkab silma, et ViruNigulas on nimisõna tüvevokaal -a ('laima); sama teave, kuid piirava levikumärgendita, leidub ka Wiedemanni sõnaraamatus: laim : laimu laima 'põlgus, halvakspanu, alavääristamine, teotus, laimamine / Verachtung, Herabwürdigung, Schande, Verläumdung, Verschmähung' (Wiedemann 1973 [1893]: 450).

Eesti laimama-verbil on vasteid soome murdekeeles, mis seni ei ole etümoloogide vaatevälja veel trehvanudki, nt Kallivere (Eesti Ingeris kõneldud soome kagumurre) laimata: omii maita kiittää toisem maita laimajaa 'omi maid kiidab, teiste maid laidab (mustab)' (kas eestipärasus?), Pielisjärvi (Põhja-Karjala savo murre) laehmata: vähän aejam perästä alettaam minniintä (= miniää) talossa laehmata 'natukese aja pärast hakatakse miniat talus laimama (halvustama)' ja võib-olla ka soome keele 
põhjamurdes (sm meänkieli) registreeritud laimistaa 'laita, maha teha; alahinnata / moittia; väheksyä, nt Ylitornio täälä vähä Venäjää laimistethiin 'siin Venemaad pisut alahinnati' (SMS).

Valmiera piirkonnas kõneldud läti murdekeelest on kirja pandud üliharuldased laimèt ja laimēties 'sõimama', mis on ilmsed eestipärasused (Kagaine 2004: 118-119). Heikki Ojansuu (1915: 162, 1916: 115, 155) on oletanud, et sm laimin, nt väljendis lyödä laimin jt 'hooletusse jätta, tegemata jätta, kahe silma vahele jätta, (juhust) mööda minna lasta' lähtub võib-olla eesti sõnast laim : laimu. Oletus ei ole usutav ei semantika ega tüvevokaali tõttu ja soome etümoloogiasõnaraamatud seda etümologiseerimiskatset ootuspäraselt ka ei nimeta (SKES 2: 270 sub laimi 'vaikne koht merel; järellainetus'; SSA 2: 37 sub laimea 'lahja, lahjendatud'; Häkkinen 2004: 559560 sub laimea). laimama-perre ei kuulu ka vdj laimata : laimaan 'äiata, virutada / шлёпать' (VKS 3: 27) onomatopoeetilis-deskriptiivne tüvi, millele vastab sm läimätä 'virutada, äiata, lajatada'.

Ehkki laimama päritolu on aegade jooksul püütud korduvalt lahti harutada, puudub sellel endiselt rahuldav etümoloogia. Tegu on ebaselge sõnaga, on öelnud Alo Raun (1982: 69), kuigi lisab kaheldes võrdluse liivi verbiga la’mmõ 'sõimata'; viimane on siiski läti hilislaen (vrd lt lamät id.), mitte vastupidi, nagu Lauri Kettunen (1938: 184a) on kõhklemisi oletanud. Ka Sõnaveebist ei leidu laimama päritolukirjeldust.

Teadaolevalt tegi esimese tõsise katse laimama etümoloogia väljaselgitamiseks Andrus Saareste ajakirjas Eesti Keel peaaegu 100 aastat tagasi. Ta võrdles eesti sõnu laim ja laimama läti sõnadega glaima 'nali, meelitus, lipitsus' ja glaimot 'naljatama, meelitama, lipitsema, paitama' ning iseloomustas põgusalt nende indoeuroopa tausta, juhtides tähelepanu tõigale, et võrdluseks esitatud sõnadega on muuhulgas samatüvelised lt gliemezis, glieme 'tigu, teokarp', gliemis 'uss, vagel; tigu, teokarp' [läti näidete kirjapilt kaasajastatud], visl kleima, vüsks kleimen 'ära määrima'. Saareste arvates „ei ole laenatud lätist mitte uuemal ajal, vaid ajajärgul, mil viimases ei oldud veel hakatud tähendatud tüve (algselt 'määrima, mustama') tarvitama irooniliselt, antifraasina tähenduses 'meelitama, kallistama' [---]". Kuna laenualuseks pakutud lt glaima etümoloogiline seos tigu tähistavate sõnadega on tundunud Saarestele väga võõrastav, on ta samas „teatava reservatsiooniga” pakkunud võrdlust leedu verbiga laiminti 'õnnistama; õnne soovima; edeneda laskma'. (Saareste 1923: 10-12)

Julius Mägiste ei ole Saareste ülalkirjeldatud seisukohti heaks kiitnud, ta ei mainigi neid (EEW 4: 1215 sub laimama). Mägiste on oletanud, et laimama on võib-olla tüvesuguluses laitma-verbiga 'maha tegema, halvustama, vigu leidma' (seisukoht, mille oli möödaminnes esitanud juba Ojansuu 1915: 162) ja tuletatud verbaalnoomenist laima; juhul kui laitma ja laimama on tüvesuguluses, on need tuletised keelest kadunud (,von einem verschollenen”) sõnatüvest la(j)i- (EEW 4: sub laitma). Mägiste kahtlused on põhjendatud: laimama ja laitma ei ole semantilisest lähedusest hoolimata tüvesugulased. Verbile ee laitma ning sm vkrj ja mrd laittaa id. (vasted samuti liivi, vadja ja isuri keeles) on Jorma Koivulehto (1999: 228) esitanud küllalt usutava baltoslaavi etümoloogia: bltsl *lāje/a-, vrd vn лáяms 'haukuma, klähvima; sõimama', ld lóti (lója, lójo) 'haukuma; sõimama, laimama', lt lãt (lāj, lāja) id. Varem 
on laitma-verbile esitatud germaani etümoloogia (vt täpsemalt LÄGLOS 2: 158159).

Saareste ja Mägiste seisukohti on põgusalt refereerinud ETY.

Leian, et Saareste on olnud õigel teel ja lahendusele vägagi lähedal, püüdes laimama-verbi siduda balti vastetega. Ta on pidanud silmas ai-diftongilist laenualust ja jõudnud nii paratamatult läti vasteteni glaima, glaimot. Läänemeresoome keelte vanade balti laenude hulgas on ai-diftongilisi juhte, mille etümoloogilised jätkajad tänapäeva balti keeltes on ie- resp. ei-diftongilised (probleemi olemuse kohta vt Vaba 2015: 55-56). Mõned näited: ee kõik, sm kaikki jt < blt *kaika- *keikā, vrd ld kieka '(suur) hulk, kogus', kiekas 'kui palju, kui suur', kiek 'kui palju', lt arh ciek 'kui palju'; ee lahja, Lõ laih 'kõhn', sm laiha id. < blt *laisa- *leisa-, ld liesas 'lahja, kõhn', lt liess id.; ee vkrj mrd paimendama 'loomi karjatama, kaitsma, valvama', sm paimen 'karjane' < blt *paimēn, vrd ld piemuo : piemens 'karjane'; ee mrd raid 'remmelgas', sm raita id. ? < blt * preid- *pried-, vrd lt priede, arh prieda 'mänd', mpr Preydazare (järv); sm mrd vaikku 'jõud, vägi', vaikuttaa 'mõju, toimet avaldada' < blt *vaik(a)*veika, vrd ld vieka, viekas 'jõud, elujõud, tugevus', veikti (veikia, veikè) 'tegutsema, töötama; mõjutama', lt veikt (veic, veica) 'täitma, teostama, sooritama'. Oletan, et ee laimama on vana balti laen, mis on lähtunud laenualusest ${ }^{*}$ glaima- resp. ${ }^{*}$ gleima-. Balti laenualuse jätkajaid tänapäeva balti keeltes on nt ld gléimoti 'mustama, reostama, rüvetama, roojastama, määrima; (refl) kleepuma', gléimèti 'limaga, mustusega kattuma', gleima, gleime 'lima, ila', gleimotis 'limaseks, kleepuvalt libedaks muutuma' (LKŽ), lt mrd gliemas pl 'kleepuv vedelik', gliema 'limane mustus, lima; vihmauss', gliemēt, gliemèt 'limaseks, libedaks muutuma', gliema 'lima, röga', gliemis 'uss, vagel, tõuk; tigu, teokarp, mollusk, limune' (ME 1: 628-629, 633; EH 1: 394; LEW 1: 157 sub gliêti; LEV 1: 298-299 sub glaimot, 300 sub gliemis); nende võimalik indoeuroopa arhetüüp on `glei-m 'kleepuma, määrima' (Pokorny 1949: 364).

Samatüveline kui laim ja laimama on eeLõ (konna) laimõ : 'laimõ 'konnakudu', mis EMS-i andmeil on registreeritud üksnes Võrumaal Harglas ja mis seni pole etümoloogide vaatevälja sattunud. Kuna see nimisõnatüvi leidub ka Urvaste pastori Johannes Gutslaffi grammatika sõnastikuosas - Schleim ['lima'] Laim / a (Gutslaff 1648) -, siis võib arvata, et sõna levik pidi minevikus olema ulatuslikum. Hella Keem (1998: 331) iseloomustab Gutslaffi sõnastikku nii: „Põhiliselt on meil siin tegemist üsna vanapärase Tartu murde sõnadega. [---] Seejuures ei tohi unustada, et Urvastes nagu Võru murdes üldse on kasutusel ka kogu Tartu murde vanapärane sõnavara, teadagi arhailisemal kujul."

Oletan, et kõne all on läänemeresoome kontraktaverbidega kohanenud verbilaen laimama : laimata (Wiedemanni sõnaraamatus rööpselt küll ka laimama : laimada), millest on tuletatud verbaalnoomen laim : laima ja noomeniliitega -u laim : laimu (vrd hakkama: hakata $\Longrightarrow$ hakk: haka ja hakk: haku 'hakatus, algus' Wiedemann 1973 [1893]: 19). Etümoloogilise analüüsi toel rekonstrueeritav sisuplaan kõneleb sellest, et laimama väljendab tegevust, kus häbistatav isik valatakse üle - küllap verbaalselt - ebameeldiva kleepuva vedeliku või limaga. Sisuplaanilt samasuunalised ja etümoloogi abitagi mõistetavad laimamist väljendavad verbid on nt mustama, tõrvama, määrima või veelgi jõulisemad soppa kaela loopima, poriga pilduma või 
koguni täis pasandama (vt laimama sünonüümirida eespool). Lisaselgitust või etümoloogi tuge vajavad nähtavasti samasisulised ee teotama $\Longleftarrow$ tigu : teo'mustus, sõnnik; limune (vrd lima)', mrd kudu kandma: Kaarma keib küla kaudu teite pezle kudu kandmas (EMS), vrd (kala-, konna)kudu, reotama < rigu : reo 'risu, kola', sõonnama $\Longleftarrow$ sõõn 'mustuse triip, viir' jms (VMS). Identseid näited võib vaevata tuua naaberkeeltest ja ilmselt kaugemaltki, mis kõneleb sellest, et tegu on semantilise universaaliga; mõned näited oleksid sm mustata $\Longleftarrow$ musta 'must, häbiväärne', loata : lokaan $\Longleftarrow$ loka 'pori, muda, kõnts vms', lt apsplạdìt $\Longleftarrow$ splaudas 'sülg, ila', vn сквернить $\Longleftarrow$ скверна 'pori, mustus'.

\section{VÕRGUMATERJALID}

EKSS = Eesti keele seletav sõnaraamat. http://www.eki.ee/dict/ekss

EMS = Eesti murrete sõnaraamat. http://www.eki.ee/dict/ems

ERA = Eesti rahvalaulude andmebaas. http://www.folklore.ee/regilaul/andmebaas

Esterm = Eesti Keele Instituudi mitmekeelne terminibaas. http://termin.eki.ee/esterm

ETY = Eesti etümoloogiasõnaraamat. http://www.eki.ee/dict/ety

LKŽ = Lietuvių kalbos žodyno. Kd I-XX, 1941-2002. Elektroninio varianto I leidimas 2005. http://www.lkz.lt

Piiblisõnastik = Eesti piiblitõlke ajalooline konkordants. https://www.eki.ee/piibel

SMS = Suomen murteiden sanakirja. http://kaino.kotus.fi/sms

Sõnaveeb = EKI ühendsõnastik 2020. https://sonaveeb.ee

SYS = Sünonüümisõnastik. http://www.eki.ee/dict/sys

VMS = Väike murdesõnastik. http://portaal.eki.ee/dict/vms

\section{KIRJANDUS}

EEW = Julius Mägiste, Estnisches etymologisches Wörterbuch. Kd 1-12. Helsinki: FinnischUgrische Gesellschaft, 2000.

EH = Jānis Endzelīns, Edīte Hauzenberga, Papildinājumi un labojumi K. Mülenbacha Latviešu valodas vārdnīcai. Kd 1-2. Rịgā: Herausgegeben vom lettischen Kulturfonds / Grāmatu apgāds, 1934-1946.

ERL = Eesti rahvalaulud. Kd III, v 1. Antoloogia. Toim Ülo Tedre. Tallinn: Eesti Raamat, 1971.

Gutslaff, Johannes 1648. Observationes grammaticae circa linguam Esthonicam. Dorpati Livonorum: Excudebat Johannes Vogel / Acad. Typogr.

Häkkinen, Kaisa 2004. Nykysuomen etymologinen sanakirja. Juva: WSOY.

Kaalep, Heiki-Jaan; Muischnek, Kadri 2002. Eesti kirjakeele sagedussõnastik. Tartu: [Tartu Ülikool].

Kagaine, Elga 2004. Lokālie somugrismi latviešu valodas Ziemel̦rietumvidzemes izloksnēs. Rịga: Latvijas Universitātes Latviešu valodas institūts.

Keem, Hella 1998. Johannes Gutslaffi grammatika eesti keel ja Urvaste murrak. - Johannes Gutslaff. Observationes grammaticae circa linguam Esthonicam. Grammatilisi vaatlusi eesti keelest. (Tartu Ülikooli eesti keele õppetooli toimetised 10.) Tartu: Tartu Ülikool, lk $317-332$. 
Kettunen, Lauri 1938. Livisches Wörterbuch mit grammatischer Einleitung. (Lexica Societatis Fenno-Ugricae V.) Helsinki: Suomalais-Ugrilainen Seura.

Koivulehto, Jorma 1999. Verba mutuata. (Suomalais-Ugrilaisen Seuran toimituksia 237.) Helsinki: Suomalais-Ugrilainen Seura.

LEV = Konstantīns Karulis 1992. Latviešu etimologijias vārdnīca. Kd 1-2. Rīga: Avots.

LEW = Ernst Fraenkel 1962-1965. Litauisches etymologisches Wörterbuch 1-2. Heidelberg: Carl Winter, Universitätsverlag, Göttingen: Vandenhoeck \& Ruprecht.

LÄGLOS = Andries D. Kylstra, Sirkka-Liisa Hahmo, Tette Hofstra, Osmo Nikkilä, Lexikon der älteren germanischen Lehnwörter in den ostseefinnischen Sprachen. Kd 2. Amsterdam-Atlanta: Rodopi, 1996.

ME $=$ K. Mīlenbacha Latviešu valodas vārdnīca. Kd 1-4. Redig̣ējis, papildinājis, turpinājis J. Endzelīns. Rīgā: Herausgegeben vom lettischen Bildungsministerium / Herausgegeben vom lettischen Kulturfonds, 1923-1932.

Ojansuu, Heikki 1915. Beiträge zu den finnisch-germanischen Berührungen. - Neuphilologische Mitteilungen, kd XVII, nr 7-8, lk 157-163.

Ojansuu, Heikki 1916. Suomalais-virolaiset kielelliset kosketukset. I. Viron kielen vaikutus suomeen. - H. Ojansuu, Suomen kielen tutkimuksen työmaalta. Sarja esitelmiä I. Jyväskylä: Gummerus, lk 98-205.

Pokorny, Julius 1949-1959. Indogermanisches etymologisches Wörterbuch. Kd 1-2. Bern: A. Francke AG Verlag.

Raun, Alo 1982. Eesti keele etümoloogiline teatmik. Rooma-Toronto: Maarjamaa.

Saareste, Andrus 1923. Etümoloogilised märkused III. - Eesti Keel, nr 1, lk 10-15.

SKES $=$ Y. H. Toivonen, Erkki Itkonen, Aulis J. Joki, Suomen kielen etymologinen sanakirja. Kd 2. (Lexica Societatis Fenno-Ugricae XII2.) Helsinki: Suomalais-Ugrilainen Seura, 1958 .

SSA = Suomen sanojen alkuperä. Etymologinen sanakirja. Kd 2. 2. tr. (Suomalaisen Kirjallisuuden Seuran toimituksia 556. Kotimaisten kielten tutkimuskeskuksen julkaisuja 62.) Peatoim Ulla-Maija Kulonen. Helsinki: Suomalaisen Kirjallisuuden Seura, Kotimaisten kielten tutkimuskeskus, 2001.

Thor Helle, Anton 1732. Kurtzgefaßte Anweisung Zur Ehstnischen Sprache, in welcher mitgetheilet werden I. Eine Grammatica, II. Ein Vocabvlarivm, III. Proverbia, IV. Ænigmata, V. Colloqvia. Halle: Gedruckt bey Stephan Orban.

Vaba, Lembit 2015. Sõna sisse minek. (Eesti Teaduste Akadeemia Emakeele Seltsi toimetised 73.) Tallinn: Eesti Teaduste Akadeemia Emakeele Selts.

Vestring, Salomo Heinrich 1998 [1710-1730]. Lexicon Esthonico Germanicum. [Võrguteavik.] Tartu: Eesti Kirjandusmuuseum.

VKS = Vadja keele sõnaraamat. Kd 3. Toim Elna Adler, Merle Leppik. Tallinn: Eesti Keele Instituut, 1996.

Wiedemann, Ferdinand Johann 1973 [1893]. Estnisch-deutsches Wörterbuch. Vierter unveränderter Druck nach der von Jakob Hurt redigierten Auflage. Tallinn: Valgus. 
arh $=$ arhailine keelend; $\mathbf{b l t}=($ alg $)$ balti keel; $\mathbf{b l t s l}=$ baltoslaavi algkeel; $\mathbf{e e}=$ eesti keel; (ee)Lõ = lõunaeesti murdekeel; ld = leedu keel; $\mathbf{l t}=$ läti keel; $\mathbf{l v}=$ liivi keel; $\mathbf{m p r}=$ muinaspreisi keel; $\mathbf{m r d}=$ murdesõna; $\mathbf{p l}=$ pluural; refl $=$ refleksiiv; $\mathbf{s m}=$ soome keel; $\mathbf{v a n}=$ vananenud; $\mathbf{v d j}=$ vadja keel; $\mathbf{v i s l}=$ vanaislandi keel; $\mathbf{v k r j}=$ vana kirjakeel; $\mathbf{v n}=$ vene keel; vüsks = vanaülemsaksa keel.

Lembit Vaba (snd 1945), PhD, Läti Teaduste Akadeemia välisliige, phorest45@gmail.com

\section{What is laim and what does laimama mean in Estonian?}

Keywords: Estonian, Finnic languages, lexical history, Baltic loanwords

In the article, the Baltic etymology ${ }^{*}$ glaima- $\sim{ }^{*}$ gleima- is suggested for the Estonian verb laimama 'to spread a lie or a shameful fabrication about someone, defame, slander.' Other etymological descendants current in modern Baltic languages include, e.g., Lith. gléimoti 'to smear, soil, besmirch, befoul, pollute; to stick', gleima 'slime; saliva', Latv. dial. gliema 'slimy dirt, slime; earthworm' etc. It is pointed out that Est. obsol. laim : laima 'slander' is a verbal noun, whence the noun laim : laimu id has been derived by means of the suffix $-u$. As revealed by etymological semantic analysis, the verb laimama refers to an activity resulting in the defamed person being poured over with an unpleasant sticky liquid or slime. Other expressions with a similar motivation can be found in Estonian as well as in the neighbouring languages.

Lembit Vaba (b. 1945), PhD, Foreign Member of the Latvian Academy of Sciences, phorest45@gmail.com 